\title{
Experimental Investigation of Convection Heat Transfer in the Transition Flow Regime of Aluminium Oxide-Water Nanofluids in a Rectangular Channel
}

\author{
Sohaib Osman, Mohsen Sharifpur*, Josua P Meyer \\ Department of Mechanical and Aeronautical Engineering, University of Pretoria, Private Bag X20, Hatfield \\ 0028, Pretoria, South Africa
}

\begin{abstract}
The growing demand for energy worldwide requires that attention be given to designing and operating heat exchangers and thermal devices to utilise and save thermal energy. There is a need to find new heat transport fluids with better heat transfer properties to increase convective heat transfer, and nanofluids have been shown to be good alternatives to conventional heat transport fluids. Although extensive research has been done on the properties of nanofluids in recent decades, there is still a lack of research on convection heat transfer involving nanofluids, particularly in the transitional flow regime. This study investigated the convective heat transfer of a one-step prepared alumina-water nanofluid. A uniformly heated rectangular channel was experimentally investigated. Nanofluids with volume concentrations of $0.3,0.5$, and $1 \%$ were used, and a Reynolds number range of 200-7 000 was considered, which included laminar and turbulent flows, as well as the transition regime from laminar to turbulent flow. The temperatures and pressure drops were measured to evaluate the heat transfer coefficients, Nusselt numbers, and pressure drop coefficients. The results showed enhancements of the heat transfer coefficients for the nanofluids used. The $1.0 \%$ nanofluid showed the maximum enhancements, with values of 54\% in the transition flow regime and $11 \%$ in the turbulent regime. The convective heat transfer efficiency in the transition flow regime was observed to be better than those in the turbulent and laminar flow regimes.
\end{abstract}

KEY WORDS: Convection, Heat transfer enhancement, Nanofluids, Aluminium oxide, Transition

\section{INTRODUCTION}

Enhancing the heat transfer rate is one of the main issues at the design stage of different thermal devices for various industries, including the transfer rates in chemical processes, and heating and cooling processes. Several techniques have been studied and developed to reduce the design and operation costs. All of these techniques revolve around a compromise between the minimisation of the flow resistance and the enhancement of the heat transfer coefficients. Therefore, it is vital to develop techniques to enhance the heat transfer rate in heat exchangers, while attempting to keep the pressure drop as low as possible.

Because of the increasing demand for improvements in a heat exchanger's performance, new heat transfer transport fluids called nanofluids were introduced towards the end of the last century. The term 'nanofluid' was first introduced by Choi in 1995 [1], after which many researchers investigated (i) the preparation and thermophysical properties of nanofluids [2-7], (ii) forced convection using nanofluids in heat exchangers [814], and (iii) the natural convection of nanofluids in cavities [15-17].

Pak and Cho [18] experimentally measured the heat transfer and friction coefficients of $\mathrm{Al}_{2} \mathrm{O}_{3}-\mathrm{water}$ and $\mathrm{TiO}_{2}$-water nanofluids for a fully developed turbulent flow. The addition of the $\mathrm{Al}_{2} \mathrm{O}_{3}$ nanoparticles resulted in a $45 \%$ enhancement in the heat transfer coefficients at a volume concentration of $1.3 \%$, with a $75 \%$ enhancement at a concentration of $2.7 \%$.

*Corresponding Author: mohsen.sharifpur@up.ac.za 
Wen and Deng [19] investigated the heat transfer augmentation provided by $\mathrm{Al}_{2} \mathrm{O}_{3}$-deionised water nanofluids in the laminar flow region, considering volume concentrations of $0.6,1$, and $1.6 \%$. The local heat transfer coefficient results for the three nanofluids showed enhancements in the heat transfer compared with that for water. The enhancement was significant in the entrance region, with a value of $45 \%$, and decreased towards the exit of the test section to $14 \%$. It was suggested that this heat transfer improvement was the result of particle movements and the reduction of the boundary layer thickness.

Anoop et al. [20] performed experiments to investigate the influence of the particle size on the heat transfer using $45 \mathrm{~nm}$ and $150 \mathrm{~nm} \mathrm{Al}_{2} \mathrm{O}_{3}$ nanoparticles and weight concentrations of 1, 4, and 6\%. Both sizes of $\mathrm{Al}_{2} \mathrm{O}_{3}$ nanoparticles showed the potential to increase the heat transfer. The $45 \mathrm{~nm}$ nanofluid was found to be better than the $150 \mathrm{~nm}$ nanofluid as far as the heat transfer was concerned. Heat transfer correlations were developed for both nanofluids.

Hwang et al. [21] measured the convective heat transfer and pressure drop in the laminar flow regime in an experiment with an $\mathrm{Al}_{2} \mathrm{O}_{3}$ water-based nanofluid prepared using a two-step method. The covered volume concentration had a range of $0.01-0.3 \%$. It was found that the heat transfer coefficient was increased by $8 \%$ when using the $0.3 \%$ concentration.

Sahin et al. [22] performed experiments with an $\mathrm{Al}_{2} \mathrm{O}_{3}$ aqueous nanofluid. Their tests were carried out using volume concentrations of $0.5,1,2$, and $4 \%$ in a circular pipe. It was observed that the heat transfer increased when the Reynolds number increases. It was also noticed that a volume concentration increase contributed to a heat transfer improvement of up to $1 \%$. For a volume concentration higher than $1 \%$, the viscosity increase was much higher than the increase in the thermal conductivity, which negatively affected the heat transfer.

Liu and $\mathrm{Yu}$ [23] conducted an experimental study on the single-phase forced convection heat transfer of an $\mathrm{Al}_{2} \mathrm{O}_{3}$-water nanofluid in a circular mini-channel. The friction factor and convection heat transfer coefficients were measured for nanofluids of various volume concentrations $(1,2,3.5$, and $5 \%)$ and compared with those of the base fluid. The Reynolds number range covered in the study was 600-4 500. The results showed that the friction factor and convective heat transfer coefficients were both less than those of water at the same Re in the transition flow, with no improvement in the turbulent and laminar regions. However, they failed to examine volume fractions smaller than $1 \%$, which is an important range for nanofluid applications.

Meyer et al. [24] experimentally investigated the convective heat transfer enhancement provided by multiwalled carbon nanotubes suspended in water, flowing in a straight horizontal circular tube. Nanofluid volume concentrations of $0.33,0.75$, and $1 \%$ were tested, and a Reynolds number range of 1000-8 000 was covered. The transition began early compared to that of water, and it was earlier when the nanofluid concentration increased. No heat transfer enhancement was found when comparing the heat transfer coefficients of the nanofluids with that of water, but there was an enhancement when comparing the Nusselt numbers of the nanofluids to that of water. The inefficiency of the nanofluids used was reported to have been because the increase in the viscosity of the nanofluid was four times the increase in the thermal conductivity.

From the above review, it is clear that only two investigations [23, 24] have been reported on the convective heat transfer of nanofluids in the transition flow regime, and both studies used circular channels. The current study was an attempt to fill the research gap in the convection heat transfer of nanofluids over the entire flow regime, including the transition flow regime. The current work differed from the previous studies [23, 24] by using nanofluids prepared with a one-step method, which is more stable than the two-step method. In addition, the test section used was a rectangular channel, and the concentrations used in this work were lower than those used in the work of Liu and Yu [23] to fill the gap in knowledge. Moreover, a Reynolds number range of 200-7 000 was investigated in this study. 


\section{EXPERIMENTAL PROCEDURES}

\subsection{Preparation and stability of nanofluids}

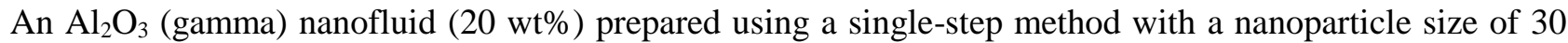
$\mathrm{nm}$ was ordered from US Research Nanomaterial (USA). This nanofluid was used because it has better stability. Volume concentrations of $0.3,0.5$, and $1 \%$ were prepared by diluting the high-concentration nanofluid. Each nanofluid was prepared by adding de-ionised water to the concentrated nanofluid and breaking down particle agglomerations using an ultrasonicator (Qsonice Q700) set at an amplitude of 60\% for $20 \mathrm{~min}$, using $3 \mathrm{~s}$ pulse on and $1 \mathrm{~s}$ pulse off intervals.

The stability of the nanofluids was ensured by measuring and observing the viscosity at a constant temperature of $25^{\circ} \mathrm{C}$ over $24 \mathrm{~h}$. Fig. 1 shows that the viscosity over time was constant, indicating the stability of the nanofluids over that period. The stability was also visually verified because no sedimentation was observed for one week.

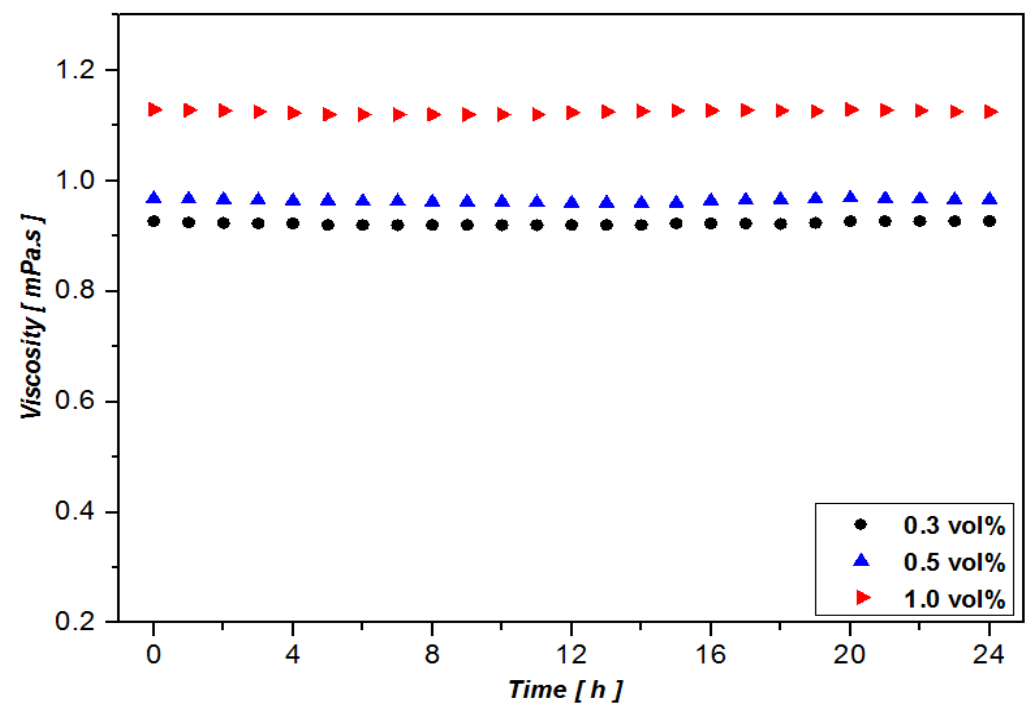

Fig. 1. Viscosity of nanofluids at $25^{\circ} \mathrm{C}$ compared to water over $24 \mathrm{~h}$

\subsection{Thermophysical properties of nanofluids}

Mintsa et al. [25] developed a correlation for the effective thermal conductivity of $\mathrm{Al}_{2} \mathrm{O}_{3}$-water nanofluids, by measuring the thermal conductivities of nanofluids at various volume concentrations up to $9 \%$, and for two different nanoparticle sizes at a wide temperature range. In this study, the thermal conductivity of the nanofluid was calculated using their developed linear correlation [25], as shown in Eq. (1).

$$
\frac{K_{n f}}{K_{b f}}=1.72 \varnothing+1
$$

The viscosity of the nanofluid was measured using a vibro-viscometer (SV-10, A\&D, Japan), with 5.0\% uncertainty at the full range. Fig. 2 compares the nanofluid viscosities to the water viscosity predicted by Popiel and Wojtkowiak [26]. It can be observed that the nanofluid viscosity increases with the volume concentration. Previous studies [27-33] reported similar results for the viscosities and thermal conductivities of nanofluids.

The density and specific heat of the nanofluid were calculated using the following mixing theory equations:

$$
\rho_{n f}=\emptyset \cdot \rho_{p}+(1-\emptyset) * \rho_{b f}
$$




$$
\left(C_{p}\right)_{n f}=\frac{\emptyset \cdot\left(\rho \cdot C_{p}\right)_{p}+(1-\emptyset) \cdot\left(\rho \cdot C_{p}\right)_{b f}}{\rho_{n f}}
$$

The properties of the water were also determined using the equation developed by Popiel and Wojtkowiak [26].

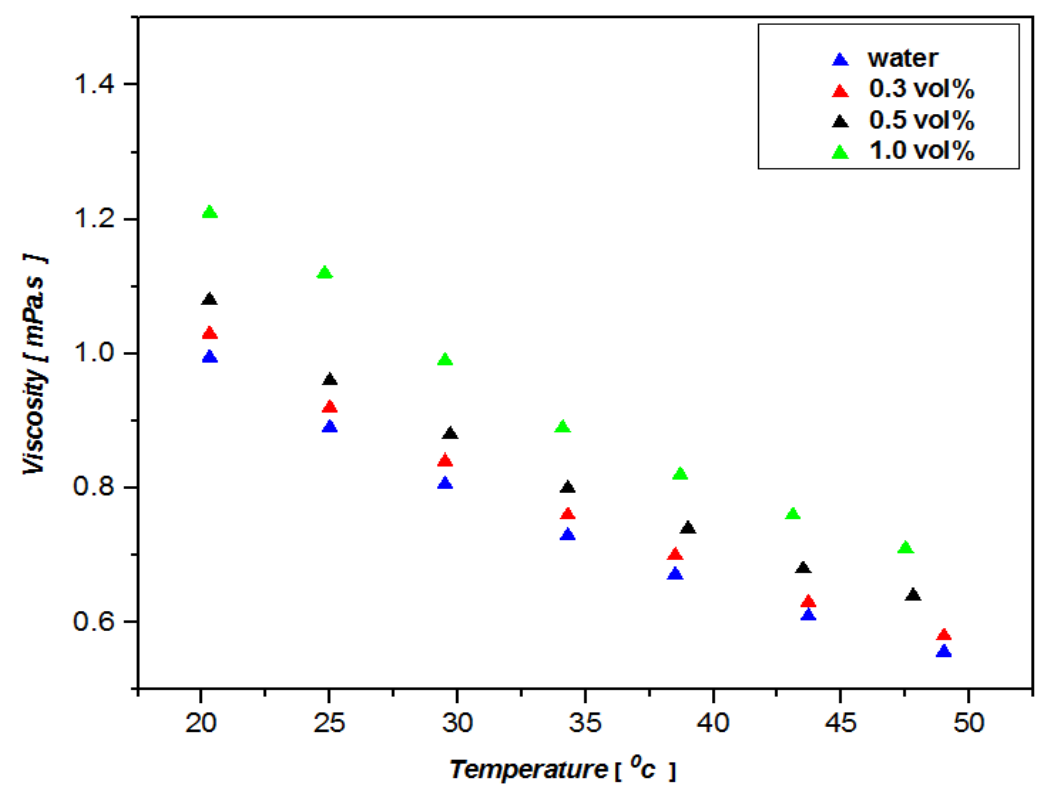

Fig. 2. Viscosities of nanofluids compared to water viscosity as function of temperature

\subsection{Experimental set-up}

As shown in Fig. 3, the test rig includes a magnetic variable speed pump (2), which is used to circulate water from the supply tank (1) through the test section. The test section is connected to the power supply to produce a uniform heat flux along the test section so that the water is heated up from $T_{i}$ to $T_{e}$. To prevent the heat from being lost, the heat exchanger is insulated using thermal insulation (4) with a thickness of $50 \mathrm{~mm}$ (four layers). The water leaves the test section at a higher temperature through the flow meter (5), which is used to measure the mass flow rate.
1. Supply tank
2. Variable speed gear pump
3. Test section
4. Thermal insulation
5. Flow meter
6. Roof chiller
7. Circulation pump
8. Heat exchanger
9. Computer

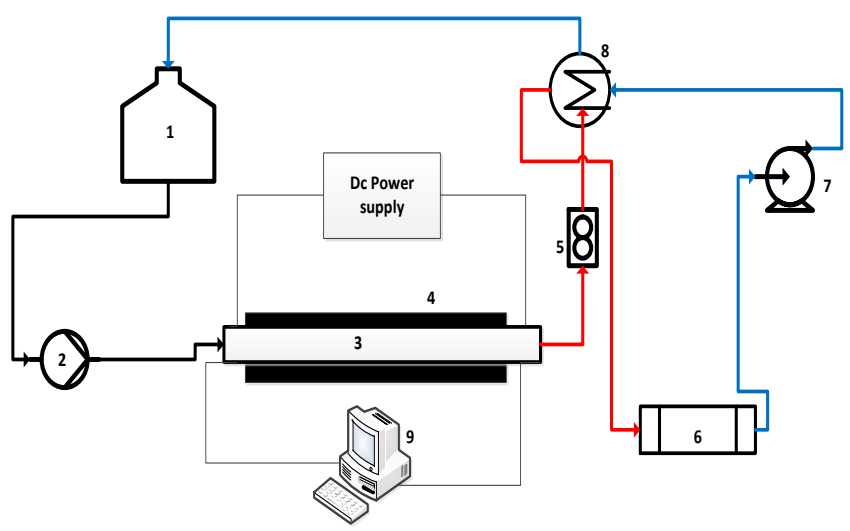

Fig. 3. Layout of experimental set-up

The temperature at the inlet to the test section is maintained at $20^{\circ} \mathrm{C}$ by cooling the hot water leaving the test section in a heat exchanger (8), where the heat is transferred to cold water from a chiller (6) through a 
circulating pump (7). The system is provided with a data acquisition system to receive signals from the thermocouples, pressure transducers, flow metres, and power supply and process these in a computer (9). A Lab View program was used to log the data.

Fig. 3 presents a schematic of the test section, which is a rectangular copper channel with a width of $8 \mathrm{~mm}$, height of $5 \mathrm{~mm}$, and length of $450 \mathrm{~mm}$. The test section is connected to the test rig using a rectangular channel with the same size and a length of $700 \mathrm{~mm}$ as a developing length to ensure that the flow is fully developed hydraulically. An acetyl bush is used to separate the developing section from the test section to avoid any axial heat transfer loss. Seven thermocouple stations (with four thermocouples at each station) are attached to the test section wall to measure the average wall surface temperature, and two thermocouples are attached to the inlet and outlet to measure the inlet and outlet fluid temperatures, respectively. Two mixers are provided at the inlet and outlet of the test section to make the temperature profile uniform at the inlet to the test section. The test section is heated by Constantine wire at $200 \mathrm{~W}$ using a DC power supply at a current of $0.75 \mathrm{~A}$ and voltage of $125 \mathrm{~V}$ (see Fig.4).

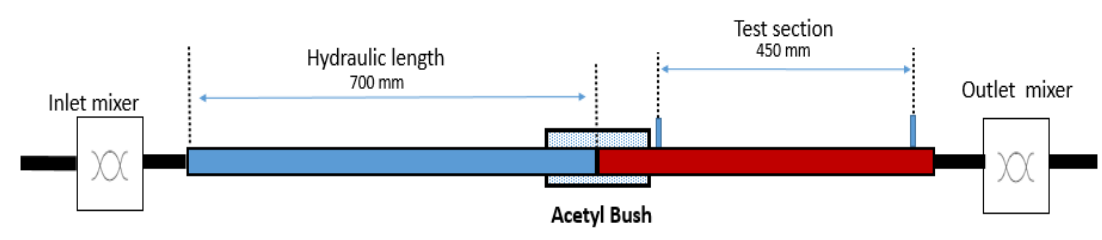

Fig. 4. Schematic of inlet and test section

\section{DATA REDUCTION}

\subsection{Pressure drop}

The average velocity (V) of a fluid with a calculated density $(\rho)$ and mass flow rate (m) across a rectangular cross-section with a measured width $(\mathrm{W})$ and measured height $(\mathrm{H})$ can be calculated using the following equation:

$$
V=\frac{\dot{m}}{\rho A_{c}}
$$

The hydraulic diameter is obtained from the following:

$$
D_{h}=\frac{4 W H}{2 W+2 H}
$$

The Darcy equation is used to calculate the friction coefficient (f) for a test section with a measured length $(\mathrm{L})$ and measured pressure drop $(\Delta P)$ :

$$
f=\frac{2 \Delta P D_{h}}{\rho L V^{2}}
$$

\subsection{Heat transfer}

The heat gained by the water $\left(Q_{\text {Water }}\right)$ as a function of the measured inlet temperature $\left(T_{I}\right)$, measured outlet temperature $\left(T_{e}\right)$, and calculated specific heat of the water $\left(C_{P}\right)$ is found as follows: 


$$
\dot{Q}_{\text {water }}=\dot{m} \cdot C_{P} \cdot\left(T_{e}-T_{i}\right)
$$

The heat flux $(\dot{q})$ is given by the following:

$$
\dot{q}=\frac{\dot{Q}_{w a t e r}}{A_{s}}
$$

where the heat transfer area is

$$
A_{s}=(2 W+2 H) L
$$

The local mean temperature can be obtained from the following:

$$
T_{m}(x)=T_{i}+\frac{\dot{q} x(2 W+2 H)}{\dot{m} C_{P}}
$$

The local heat transfer coefficient can be calculated as follows:

$$
h(x)=\frac{\dot{q}}{\left[T_{w i}(x)-T_{m}(x)\right]}
$$

The Nusselt number for a fluid with a calculated thermal conductivity $(\mathrm{k})$ is found as follows:

$$
N u=\frac{h_{a v g} D_{h}}{k}
$$

The Reynolds number can be calculated using the following:

$$
R e=\frac{\rho V D_{h}}{\mu}
$$

\subsection{Uncertainty analysis}

The procedures suggested by Dunn [34] were used to calculate all of the uncertainties of the measured and calculated parameters, where all of the uncertainties were evaluated within the $95 \%$ confidence interval. Table 1 lists the instruments used to calculate the bias error in the uncertainty analysis, along with their ranges and accuracies. The uncertainties were calculated at a higher Reynolds number of 7800 and lower Reynolds number of 650. The uncertainty values of the main experimental parameters are given in Table 2 .

\section{Table 1}

Range and accuracies of instruments

\begin{tabular}{|l|l|l|}
\hline Instrument & Range & Accuracy \\
\hline Power Supply & & \\
Current & $0-12.5 \mathrm{~A}$ & $0.5 \%$ of the measured value \\
Voltage & $0-320 \mathrm{~V}$ & $0.1 \%$ of the measured value \\
\hline Thermocouples & $-200-350{ }^{\circ} \mathrm{C}$ & $0.1{ }^{\circ} \mathrm{C}$ \\
\hline Flow meter & $0-252 \mathrm{~L} / \mathrm{h}$ & $0.1 \%$ \\
\hline Pressure transducer & $0-17 \mathrm{kPa}$ & $0.16 \%$ \\
\hline
\end{tabular}




\section{Table 2}

Ranges and accuracies of instruments

\begin{tabular}{|l|l|l|l|l|l|}
\hline & $R e$ & $\Delta P$ & $f$ & $h$ & $N u$ \\
\hline High Re & $4.46 \%$ & $1.15 \%$ & 1.15 & $4.48 \%$ & $4.93 \%$ \\
\hline Low Re & $4.63 \%$ & $16.76 \%$ & 16.70 & $0.85 \%$ & $2.23 \%$ \\
\hline
\end{tabular}

\subsection{Validation}

\section{RESULTS AND DISCUSSION}

Measurements were taken in the laminar and turbulent flow regimes and compared with the correlations found in the literature. Only water was considered for validation because no other data exist for the same nanofluid and same test section geometry.

\subsubsection{Validation of friction coefficient measurements:}

The adiabatic friction coefficient results were compared to those reported by Leon and Roman [35] for laminar and turbulent flows. As respectively shown in Eq. (14) and Eq. (15), these two correlations were modified from the conventional Poiseuille correlation [36] for laminar flow and Blasius [37] correlation for turbulent flow to suit the rectangular cross-section channels:

$$
\begin{gathered}
f_{\text {lamiar }}=\frac{64}{R e^{*}} \\
f_{\text {turbulent }}=0.316\left(R e^{*}\right)^{-0.25}
\end{gathered}
$$

where $\alpha$ is the aspect ratio of the rectangular cross-section, and $R e^{*}$ is the modified Reynolds number, which can be found as follows:

$$
R e^{*}=\frac{R e}{2 \alpha^{0.16}}
$$

Fig. 5 shows the friction factor data for the water compared to the correlation of Leon and Roman (laminar) [35]. The correlation predicted the results very well because the average deviation was $1.7 \%$. On the turbulent side, the results showed good agreement with those of Leon and Roman [35] (the deviation was less than $1.3 \%$ over the entire turbulent regime).

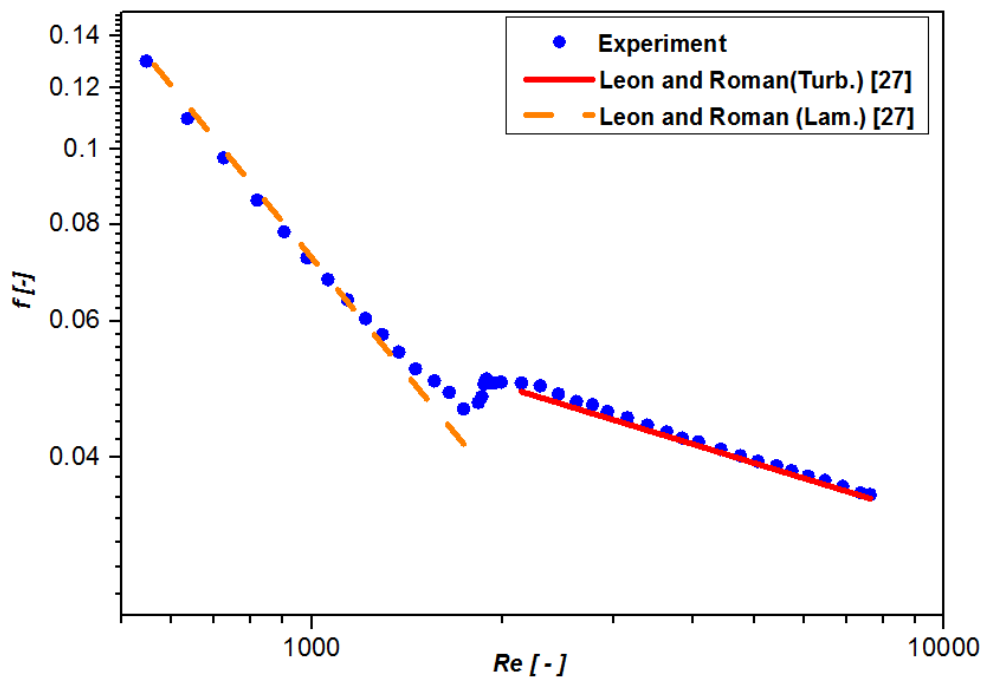


Fig. 5. Adiabatic friction coefficient results in rectangular channel compared to theoretical correlations

The transitional flow regime in the rectangular channels started at a Reynolds number of 1827 , as shown in Fig. 5 and Fig. 6. The critical Reynolds number (where the transition started) in a circular tube is 2300 , as reported by Cengel [38]. The earlier transition was due to the geometry of the test section used and the type of inlet because the inlet of the test section had significant effects on the critical Reynolds number, transition pattern, and transition length [39].

\subsubsection{Validation of Nusselt number measurements}

The Nusselt number results, as shown in Fig. 6, were compared with the values predicted by Morcos and Bergles [40] on the laminar side, and the agreement was very good, with an average deviation of $0.7 \%$. The average Nusselt number, as shown in Fig. 6, correlated very well with the correlation of Everts and Meyer [41], which

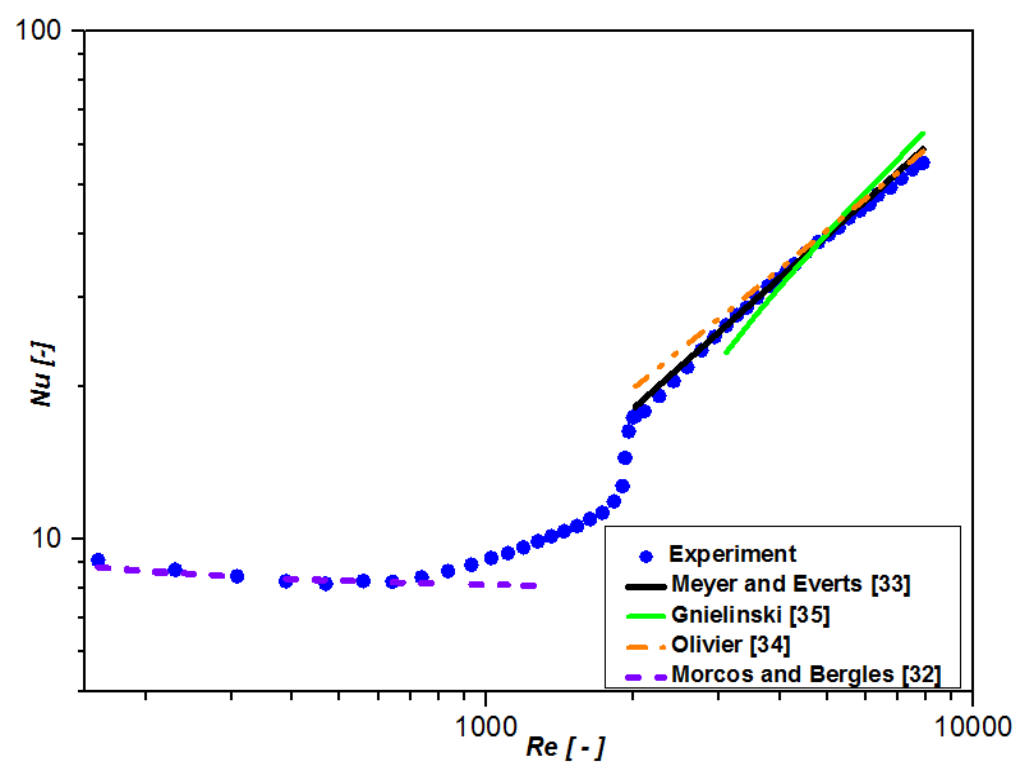

Fig. 6. Average Nusselt number results compared to theoretical correlations

over-predicted the results by an average of $1.8 \%$. The correlation of Olivier [42] over-predicted the data by an average of $3.8 \%$, which was a good prediction. Gnielinski [43] under-predicted the data by $6 \%$ in the Reynolds number range of $3000-5000$, and over-predicted the data by $7 \%$ for Reynolds numbers greater than 5 000. The correlations of both Olivier [34] and Gnielinski [35] failed to predict the data on the turbulent side between Reynolds numbers of 2000 and 3000 because they under-predicted the data in this range by $12 \%$ and $21 \%$, respectively. This significant difference occurred because the two correlations were developed to predict the turbulent region of flow for Reynolds numbers greater than 3000 .

\subsection{Nanofluid results \\ 4.2.1 Heat transfer results}

Fig. 7 and Fig. 8 present the average heat transfer coefficients and average Nusselt number measurements of $\mathrm{Al}_{2} \mathrm{O}_{3}$-water nanofluids of $0.3,0.5$, and 1.0 vol\% compared to pure water in a Reynolds number range of 200-7000.

As shown in Fig. 7, the heat transfer coefficient results showed an enhancement in the heat transfer in the fully developed turbulent regime, with values of $1.0 \%$ at a Reynolds number of 6364 for the 0.3 vol\% nanofluid, $8.3 \%$ for the $0.5 \mathrm{vol} \%$, and $11 \%$ for the $1.0 \mathrm{vol} \%$. The average enhancements in the heat transfer 
coefficient in the turbulent flow regime were $3.1 \%$ for the $0.3 \mathrm{vol} \%$ nanofluid, $10 \%$ for the $0.5 \mathrm{vol} \%$, and $16 \%$ for the $1.0 \mathrm{vol} \%$ nanofluid. The average enhancements in the Nusselt number in the turbulent regime, as shown in Fig. 8, were $2.5 \%$ for the 0.3 vol $\%$ nanofluid, $8.6 \%$ for the 0.5 vol $\%$ nanofluid, and $13 \%$ for the 1.0 vol\%. The same observations of the heat transfer enhancements in the turbulent flow regime were observed by Pak and Cho [18]. The random motion of nanoparticles within the fluid decreased the thermal boundarylayer thickness and made a significant contribution to the enhancement of the convection heat transfer rate. This could be the reason behind the enhancements in the heat transfer coefficient and Nusselt number in the turbulent regime [44, 45].

Two features were observed in the transition flow regime in the rectangular channel when using the $\mathrm{Al}_{2} \mathrm{O}_{3}-$ water nanofluid. First, the critical Reynolds number (starting the transition) was earlier when using the nanofluid and occurred at a smaller Reynolds number than the pure water when a higher concentration nanofluid was used. As shown in Fig. 7 and Fig. 8, the transition began at Reynolds numbers of 1731 for the 0.3 vol\% nanofluid, 1723 for the 0.5 vol\% nanofluid, and 1705 for the $1.0 \mathrm{vol} \%$ nanofluid, and the ranges of Reynolds numbers over which the transition occurred were 125,110 , and 125 , respectively. For all three nanofluids, the transition flow regime began earlier than for pure water. This early transition could be justified by the higher viscosity of the nanofluid because a higher viscosity leads to a shift in the position of the graph in Fig. 6 to a new position, as shown in Fig. 8. This early transition feature matched that found in the work of Meyer et al. [24], where the results of the nanofluids were represented as a Re-Nu graph.

The second feature in the transition flow regime was that the enhancement of the heat transfer coefficients for the three nanofluids, with values of $15 \%, 29 \%$, and $54 \%$ for the $0.3,0.5$, and $1.0 \mathrm{vol} \%$ nanofluids, respectively.

The enhancements in the Nusselt number in the transition flow regime, as shown in Fig. 8, were found to be $14 \%$ for the $0.3 \mathrm{vol} \%$ nanofluid, $27 \%$ for the $0.5 \mathrm{vol} \%$ nanofluid, and $50 \%$ for the $1.0 \mathrm{vol} \%$ nanofluid.

A comparison of the heat transfer enhancements in the turbulent flow regime and transition flow regime revealed that the heat transfer was more enhanced in the transition regime than the turbulent regime. It is possible that the Brownian motion of the nanoparticles and the flow randomness assisted in mixing the nanoparticles with the base fluid, which contributed to the better heat transfer performance in the transition flow regime. Another reason for the better enhancement in the transition flow regime was that the addition of small particles to the base fluid suppressed turbulence by playing the role of an additional source of dissipation, as proposed by Hetsroni [46].

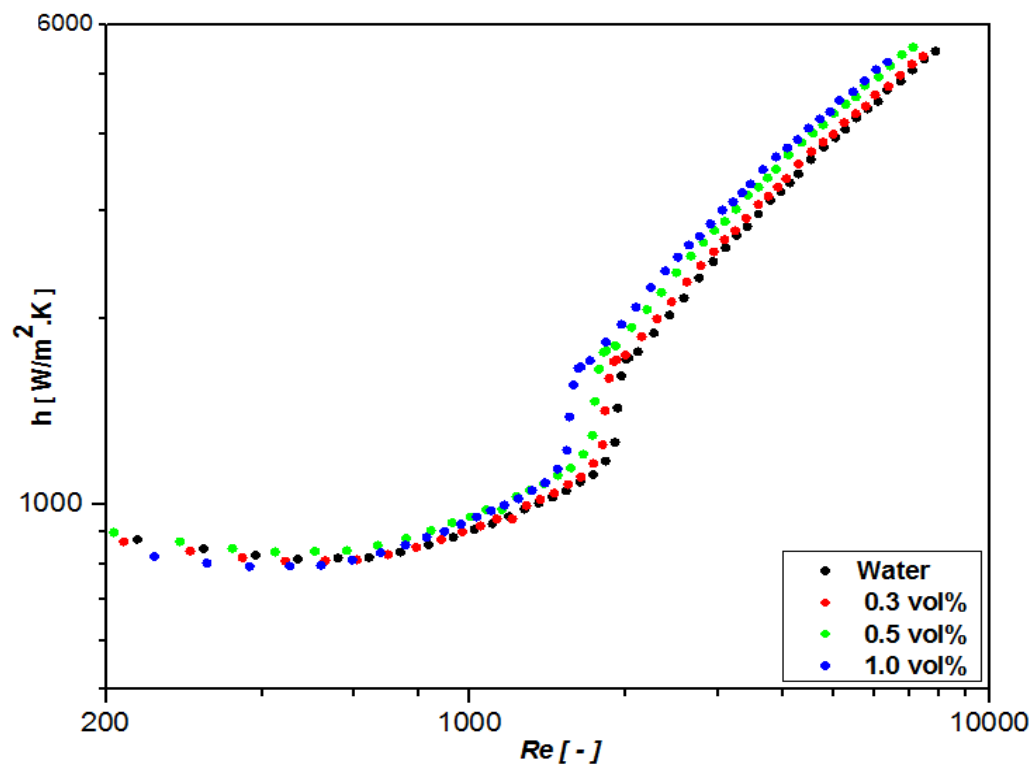

Fig. 7. Heat transfer coefficients results of nanofluids compared to water against Reynolds number 
The enhancement in the laminar region was negligible because at low Reynolds numbers an agglomeration of nanoparticles could occur in the nanofluid flow, which reduced the heat transfer enhancement. However, at high Reynolds numbers, the agglomeration effect was significantly reduced, although Hwang et al. [21] reported an enhancement in the laminar flow for a fully developed case. Their study differed from the current work because in this work the laminar flow regime was not fully developed in relation to the entrance length. In addition, the geometry of their test channel was circular, and they used a two-step preparation method for their nanofluid.

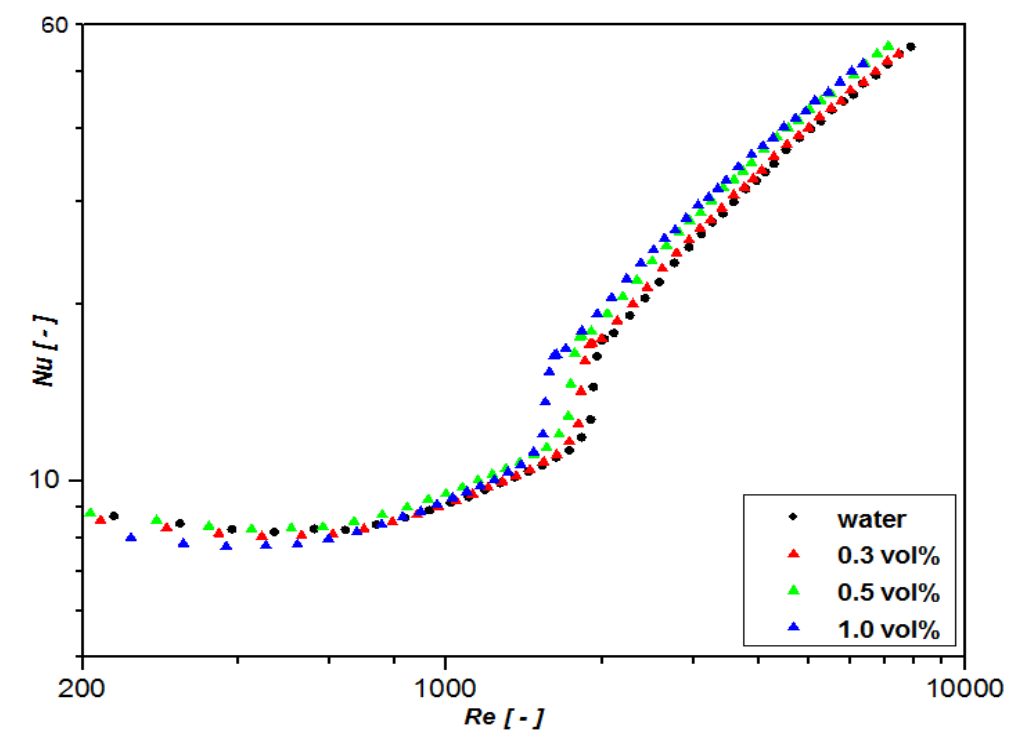

Fig. 8. Nusselt number results for nanofluids compared to water against Reynolds number

\subsubsection{Pressure drop results}

Fig. 9 presents the pressure drop for the water compared to three $\mathrm{Al}_{2} \mathrm{O}_{3}$-water nanofluids against the Reynolds number for the entire flow range. The pressure drop of the nanofluid in the turbulent flow regime increased with the volume concentration, with values of $11 \%, 19 \%$, and $46 \%$ for the $0.3,0.5$, and 1.0 vol\% nanofluids, respectively.

The increase in the pressure drop was significant in the transition flow regime, with values of $7.9 \%, 14 \%$, and $61 \%$ for the $0.3,0.5$, and 1.0 vol $\%$ nanofluids, respectively. In the laminar flow regime, the pressure drop increased by $1.8 \%$ for the $0.3 \mathrm{vol} \%, 9.3 \%$ for the $0.5 \mathrm{vol} \%$, and $29 \%$ for the $1.0 \mathrm{vol} \%$.

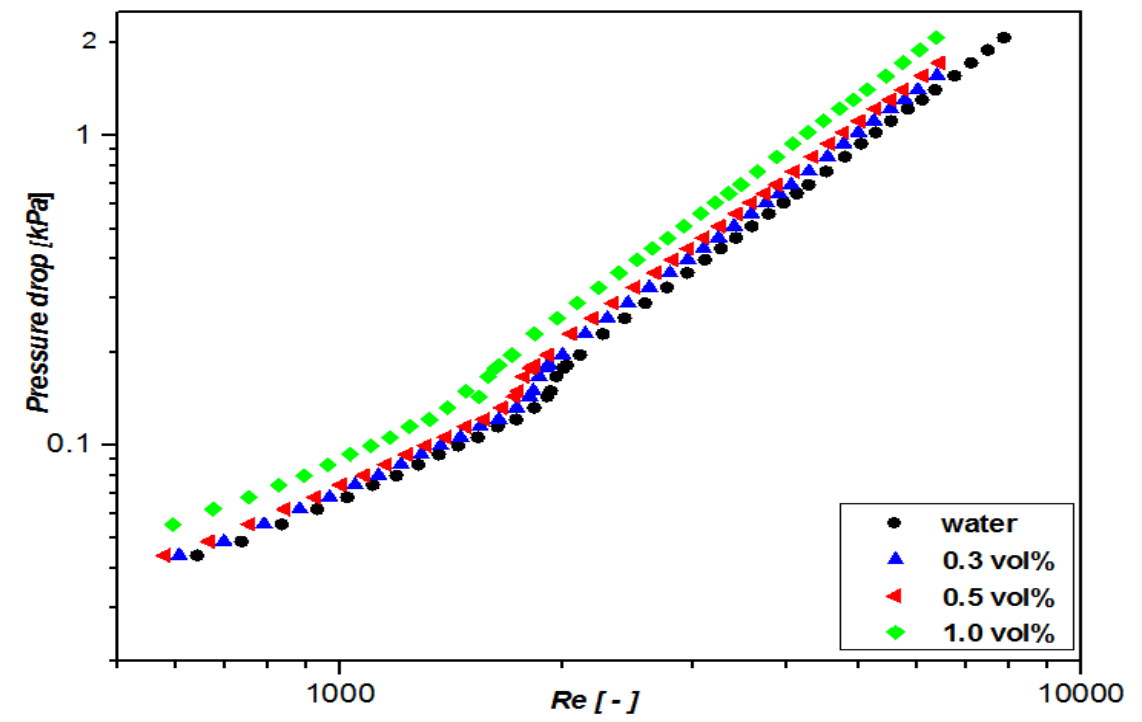

Fig. 9. Pressure drops of nanofluids compared to water against Reynolds number 


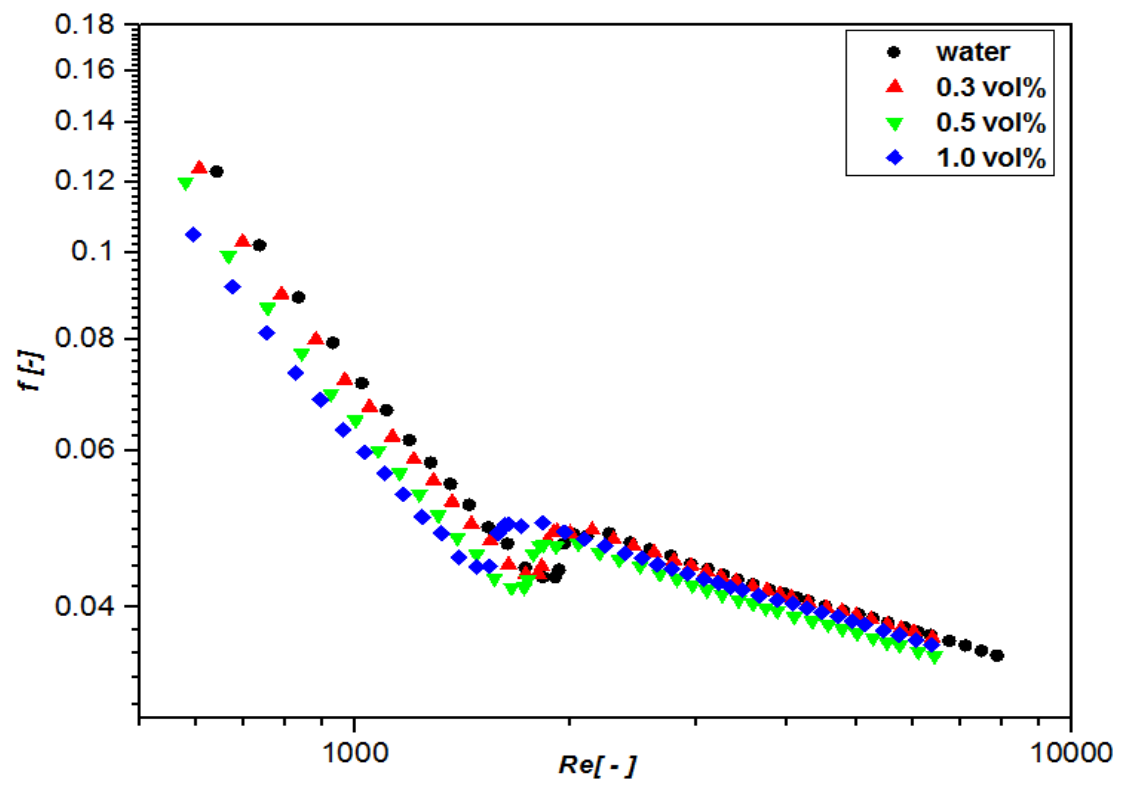

Fig. 10. Friction coefficients of nanofluids compared to water against Reynolds number

Fig. 10 shows the friction factor for the water compared to the three $\mathrm{Al}_{2} \mathrm{O}_{3}$-water nanofluids against the Reynolds number for the entire flow range. The friction factor of the nanofluid in the laminar flow regime decreased with an increase in the volume concentration, and the values for all of the nanofluids were lower than that for the pure water at the same Reynolds number. Towards the turbulent regime, the friction coefficient results for the nanofluids and water became difficult to distinguish because of the effect of the nanoparticles on the flow physics at this regime.

The transitions shown in Fig. 9 and Fig. 10 occurred at the same Reynolds number as those seen in the Nusselt number and heat transfer coefficients results, and the range of Reynolds numbers over which the transitions occurred was also the same as those seen in the Nusselt number and heat transfer coefficient results.

\subsubsection{Comparison of convective heat transfer and pumping power}

The heat transfer performance of the nanofluid could be evaluated by comparing the convection heat transfer obtained by the nanofluid to the pumping power required to send the nanofluid to the laminar, transition, or turbulent flow regime. The following expression for the convective heat transfer efficiency $(\eta)$ was used by Meriläinen et al. [47]:

$$
\eta=\frac{\left(Q_{\text {conv }}\right)_{n f} /\left(P_{\text {pumping }}\right)_{n f}}{\left(Q_{\text {conv. }}\right)_{b f} /\left(P_{\text {pumping }}\right)_{b f}}
$$

where $\mathrm{Q}_{\text {conv. }}$ and $\mathrm{P}_{\text {pumping }}$ are the convective heat transfer and pumping power, respectively; and the subscriptions $\mathrm{nf}$ and $\mathrm{bf}$ indicate the nanofluid and base fluid, respectively. 


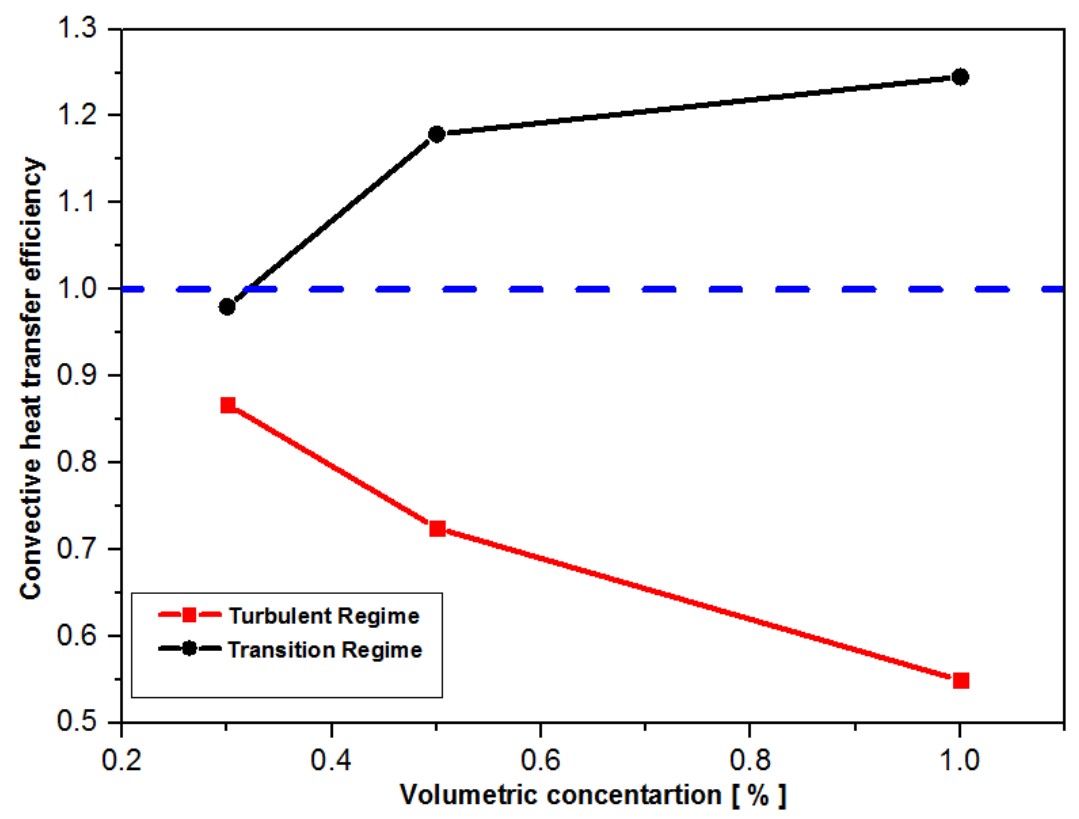

Fig. 11. Convective heat transfer efficiency of nanofluids for turbulent and transition flow regimes against volumetric concentration

The heat transfer efficiency, as defined in Eq.(17), was determined by calculating the average convection heat transfer and pressure drop values in the transition and turbulent flow regimes. The results are plotted against the nanofluid volumetric concentration in Fig. 11.

The laminar region has not been included in the comparison because of the inefficiency of the nanofluids in this regime, as stated in section 4.2.1.

Fig. 11 shows that the efficiency of the nanofluids in the transition regime was greater than unity for a volume concentration greater than $0.3 \mathrm{vol} \%$, whereas it was less than unity in the turbulent regime. These observations show that the nanofluids used were more efficient in the transition flow regime because the convective heat transfer dominated the pressure drop, and adding $\mathrm{Al}_{2} \mathrm{O}_{3}$ nanoparticles to the water was more efficient than simply increasing the flow rate of the pump.

\section{CONCLUSION}

Aluminium oxide-water nanofluids with volume concentrations of $0.3 \%, 0.5 \%$, and $1.0 \%$ were tested in a uniformly heated rectangular channel for the entire flow regime, and the following conclusions were made:

- The transition to turbulent flow in a rectangular channel started earlier than in conventional circular channels.

- The transition started earlier when using the nanofluids compared to water, as observed in both the heat transfer and pressure drop results.

- The enhancement in the heat transfer coefficient was $43 \%$ more in the transition regime than in the turbulent regime.

- The convective heat transfer efficiency was $1.3 \%$ at $1.0 \mathrm{vol} \%$ in the transition flow regime, whereas it was $0.55 \%$ at the same volume concentration in the turbulent flow regime. Thus, the pressure drop in the turbulent flow regime was found to be greater than the heat transfer, whereas in the transition regime, the heat transfer was found to be greater than the pressure drop. 
- Enhancements in the heat transfer coefficients and Nusselt number were observed in the turbulent flow regime for all three nanofluids, with a maximum enhancement of $11 \%$ when using the 1.0 vol\% nanofluid.

- No heat transfer enhancement occurred in the laminar regime for this nanofluid, and the friction factors for the nanofluids tested were significantly higher than that for pure water.

- The pressure drop increased with the volume concentration.

\section{ACKNOWLEDGEMENT}

The funding obtained from Clean Energy Research Group, at the Department of Mechanical and Aeronautical Engineering of the University of Pretoria, and the DST in South Africa, is acknowledged and appreciated.

\section{NOMENCLATURE}

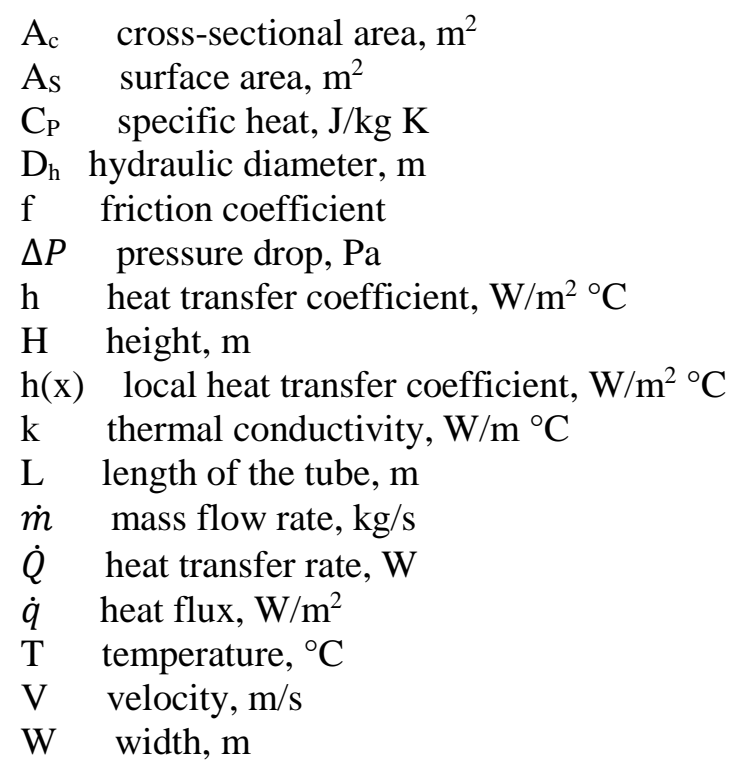

Greek symbols
$\mu \quad$ viscosity, $\mathrm{kg} / \mathrm{m} \mathrm{s}$
$\rho$ density, $\mathrm{kg} / \mathrm{m}^{3}$
$\emptyset \quad$ volume concentration
$\eta$ convective heat transfer efficiency

Non-dimensional numbers

Re Reynolds number

$\mathrm{Nu}$ Nusselt number

Subscripts

Avg. average

b bulk

bf base fluid

e exit

i inlet

nf nanofluid

$\mathrm{P}$ particles 


\section{REFERENCES}

[1] S. U. S. Choi, "Enhancing thermal conductivity of fluids with nanoparticles," in American Society of Mechanical Engineers, Fluids Engineering Division (Publication) FED, 1995, vol. 231, pp. 99-105.

[2] S. A. Adio, M. Mehrabi, M. Sharifpur, and J. P. Meyer, "Experimental investigation and model development for effective viscosity of $\mathrm{MgO}$-ethylene glycol nanofluids by using dimensional analysis, FCM-ANFIS and GA-PNN techniques," International Communications in Heat and Mass Transfer, vol. 72, no. Supplement C, pp. 71-83, 2016/03/01/ 2016.

[3] M. Sharifpur, S. A. Adio, and J. P. Meyer, "Experimental investigation and model development for effective viscosity of Al2O3-glycerol nanofluids by using dimensional analysis and GMDH-NN methods," International Communications in Heat and Mass Transfer, vol. 68, no. Supplement C, pp. 208-219, 2015/11/01/ 2015.

[4] M. Amiri, S. Movahedirad, and F. Manteghi, "Thermal conductivity of water and ethylene glycol nanofluids containing new modified surface SiO2-Cu nanoparticles: Experimental and modeling," Applied Thermal Engineering, vol. 108, no. Supplement C, pp. 48-53, 2016/09/05/ 2016.

[5] P. Garg, J. L. Alvarado, C. Marsh, T. A. Carlson, D. A. Kessler, and K. Annamalai, "An experimental study on the effect of ultrasonication on viscosity and heat transfer performance of multi-wall carbon nanotube-based aqueous nanofluids," International Journal of Heat and Mass Transfer, vol. 52, no. 21-22, pp. 5090-5101, 2009.

[6] O. A. Alawi, N. A. C. Sidik, H. W. Xian, T. H. Kean, and S. N. Kazi, "Thermal conductivity and viscosity models of metallic oxides nanofluids," International Journal of Heat and Mass Transfer, vol. 116, pp. 1314-1325, 2018/01/01/ 2018.

[7] Y. Ueki, T. Aoki, K. Ueda, and M. Shibahara, "Thermophysical properties of carbon-based material nanofluid," International Journal of Heat and Mass Transfer, vol. 113, pp. 1130-1134, 2017/10/01/ 2017.

[8] Q. Li and Y. Xuan, "Convective heat transfer and flow characteristics of Cu-water nanofluid," Science in China, Series E: Technological Sciences, vol. 45, no. 4, pp. 408-416, 2002.

[9] Y. Yang, Z. G. Zhang, E. A. Grulke, W. B. Anderson, and G. Wu, "Heat transfer properties of nanoparticle-in-fluid dispersions (nanofluids) in laminar flow," International Journal of Heat and Mass Transfer, vol. 48, no. 6, pp. 1107-1116, 2005.

[10] Y. Ding, H. Alias, D. Wen, and R. A. Williams, "Heat transfer of aqueous suspensions of carbon nanotubes (CNT nanofluids)," International Journal of Heat and Mass Transfer, vol. 49, no. 1-2, pp. 240-250, 2006.

[11] S. M. S. Murshed, K. C. Leong, C. Yang, and N. T. Nguyen, "Convective heat transfer characteristics of aqueous TiO2 nanofluid under laminar flow conditions," International Journal of Nanoscience, vol. 7, no. 6, pp. 325-331, 2008.

[12] A. A. Hussien, M. Z. Abdullah, N. M. Yusop, M. d. A. Al-Nimr, M. A. Atieh, and M. Mehrali, "Experiment on forced convective heat transfer enhancement using MWCNTs/GNPs hybrid nanofluid and mini-tube," International Journal of Heat and Mass Transfer, vol. 115, pp. 1121-1131, 2017/12/01/ 2017.

[13] M. Ahmadi and G. Willing, "Heat transfer measurement in water based nanofluids," International Journal of Heat and Mass Transfer, vol. 118, pp. 40-47, 2018/03/01/ 2018.

[14] J. Zhang, Y. Diao, Y. Zhao, and Y. Zhang, "Experimental study of TiO2-water nanofluid flow and heat transfer characteristics in a multiport minichannel flat tube," International Journal of Heat and Mass Transfer, vol. 79, pp. 628-638, 2014/12/01/ 2014.

[15] H. Ghodsinezhad, M. Sharifpur, and J. P. Meyer, "Experimental investigation on cavity flow natural convection of Al2O3-water nanofluids," International Communications in Heat and Mass Transfer, vol. 76, no. Supplement C, pp. 316-324, 2016/08/01/ 2016. 
[16] A. Brusly Solomon, J. van Rooyen, M. Rencken, M. Sharifpur, and J. P. Meyer, "Experimental study on the influence of the aspect ratio of square cavity on natural convection heat transfer with Al2O3/Water nanofluids," International Communications in Heat and Mass Transfer, vol. 88, no. Supplement C, pp. 254-261, 2017/11/01/ 2017.

[17] I. V. Miroshnichenko, M. A. Sheremet, H. F. Oztop, and N. Abu-Hamdeh, "Natural convection of alumina-water nanofluid in an open cavity having multiple porous layers," International Journal of Heat and Mass Transfer, vol. 125, pp. 648-657, 2018/10/01/ 2018.

[18] B. C. Pak and Y. I. Cho, "Hydrodynamic and heat transfer study of dispersed fluids with submicron metallic oxide particles," Experimental Heat Transfer, vol. 11, no. 2, pp. 151-170, 1998.

[19] D. Wen and Y. Ding, "Experimental investigation into convective heat transfer of nanofluids at the entrance region under laminar flow conditions," International Journal of Heat and Mass Transfer, vol. 47, no. 24, pp. 5181-5188, 2004.

[20] K. B. Anoop, T. Sundararajan, and S. K. Das, "Effect of particle size on the convective heat transfer in nanofluid in the developing region," International Journal of Heat and Mass Transfer, vol. 52, no. 910, pp. 2189-2195, 2009.

[21] K. S. Hwang, S. P. Jang, and S. U. S. Choi, "Flow and convective heat transfer characteristics of water-based Al2O3 nanofluids in fully developed laminar flow regime," International Journal of Heat and Mass Transfer, vol. 52, no. 1, pp. 193-199, 2009/01/15/ 2009.

[22] B. Sahin, G. G. Gültekin, E. Manay, and S. Karagoz, "Experimental investigation of heat transfer and pressure drop characteristics of Al2O3-water nanofluid," Experimental Thermal and Fluid Science, vol. 50, no. Supplement C, pp. 21-28, 2013/10/01/ 2013.

[23] Y. L. Liu Donga, "Single - phase thermal transport of nanofluids in a Minichannel " Journal of Heat Transfer, vol. 133, no. 3, 2011.

[24] J. P. Meyer, T. J. McKrell, and K. Grote, "The influence of multi-walled carbon nanotubes on singlephase heat transfer and pressure drop characteristics in the transitional flow regime of smooth tubes," International Journal of Heat and Mass Transfer, vol. 58, no. 1-2, pp. 597-609, 2013.

[25] H. A. Mintsa, G. Roy, C. T. Nguyen, and D. Doucet, "New temperature dependent thermal conductivity data for water-based nanofluids," International Journal of Thermal Sciences, vol. 48, no. 2, pp. 363-371, 2009/02/01/ 2009.

[26] C. Popiel and J. Wojtkowiak, "simple formulas for thermophysical properties of liquid water for heat transfer calculations " Heat transfer Eng., vol. 19, no. 3, pp. 87-101, 1998.

[27] J. C. Joubert, M. Sharifpur, A. B. Solomon, and J. P. Meyer, "Enhancement in heat transfer of a ferrofluid in a differentially heated square cavity through the use of permanent magnets," Journal of Magnetism and Magnetic Materials, vol. 443, pp. 149-158, 2017/12/01/ 2017.

[28] I. D. Garbadeen, M. Sharifpur, J. M. Slabber, and J. P. Meyer, "Experimental study on natural convection of MWCNT-water nanofluids in a square enclosure," International Communications in Heat and Mass Transfer, vol. 88, pp. 1-8, 2017/11/01/ 2017.

[29] M. Sharifpur, N. Tshimanga, J. P. Meyer, and O. Manca, "Experimental investigation and model development for thermal conductivity of $\alpha$-Al2O3-glycerol nanofluids," International Communications in Heat and Mass Transfer, Article vol. 85, pp. 12-22, 2017.

[30] S. A. Adio, M. Mehrabi, M. Sharifpur, and J. P. Meyer, "Experimental investigation and model development for effective viscosity of MgO-ethylene glycol nanofluids by using dimensional analysis, FCM-ANFIS and GA-PNN techniques," International Communications in Heat and Mass Transfer, Article vol. 72, pp. 71-83, 2016.

[31] N. Tshimanga, M. Sharifpur, and J. P. Meyer, "Experimental Investigation and Model Development for Thermal Conductivity of Glycerol-MgO Nanofluids," Heat Transfer Engineering, Article vol. 37, no. 18, pp. 1538-1553, 2016.

[32] S. A. Adio, M. Sharifpur, and J. P. Meyer, "Influence of ultrasonication energy on the dispersion consistency of Al2O3-glycerol nanofluid based on viscosity data, and model development for the required ultrasonication energy density," Journal of Experimental Nanoscience, Article vol. 11, no. 8, pp. 630-649, 2016. 
[33] S. A. Adio, M. Sharifpur, and J. P. Meyer, "Electrical Conductivity and pH of Y-Al2O3 - Glycerol Nanofluids in Einstein Concentration Regime," Heat Transfer Engineering, Article vol. 36, no. 14-15, pp. 1241-1251, 2015.

[34] P. F. Dunn, Measurement and Data Analysis for Engineering and Science, 2nd edn ed. Boca Raton: CRC Press, 2010.

[35] T. Leon and U. Roman, "Two-phase gas-liquid flow in rectangular channels " Chem. Eng. Sc., vol. 39, no. 4, pp. 751-765, 1984.

[36] J. L. M. Poiseuille, "Recherches expérimentelles sur le mouvement des liquids dans le tubes de très petits diamétres," Comptes Rendu, vol. 11, pp. 961-967, 1041-1048, 1840.

[37] P. R. H. Blasius, "Das Aehnlichkeitsgesetz bei Reibungsvorgangen in Flüssigkeiten," Forschungsheft, vol. 131, pp. 1-41, 1913.

[38] Y. A. Cengel, Heat and mass Transfer : a practical approach 3rd ed. ed. McGraw-Hill, 2007.

[39] L.-M. Tam and A. J. Ghajar, "Effect of inlet geometry and heating on the fully developed friction factor in the transition region of a horizontal tube," Experimental Thermal and Fluid Science, vol. 15, no. 1, pp. 52-64, 7// 1997.

[40] S. Morcos and A. Bergles, "Experimental investigation of combined forced and free laminar convection in horizontal tubes " Journal of Heat Transfer, vol. 97, no. 2, pp. 212-219, 1975.

[41] M. Everts and J. P. Meyer, "Relationship between pressure drop and heat transfer of developing and fully developed flow in smooth horizontal circular tubes in laminar, transitional, quasiturbulent and turbulent flow regimes " International Journal of Heat and Mass Transfer, vol. 117, no. 2018, pp. 1231 - 1250, 2017.

[42] J. A. Olivier and J. P. Meyer, "Single-phase heat transfer and pressure drop of the cooling of water inside smooth tubes for transitional flow with different inlet geometries," HVAC and R vol. 16, no. 4, pp. $471-4962010$.

[43] V. Gnielinski, "New equations for heat and mass transfer in turbulent pipe and channel flow " Int. Chem. Eng., vol. 16, no. 2, p. 10, 1976.

[44] D. Kim et al., "Convective heat transfer characteristics of nanofluids under laminar and turbulent flow conditions," Current Applied Physics, vol. 9, no. 2 SUPPL., pp. e119-e123, 2009.

[45] W. Duangthongsuk and S. Wongwises, "An experimental study on the heat transfer performance and pressure drop of TiO2-water nanofluids flowing under a turbulent flow regime," International Journal of Heat and Mass Transfer, vol. 53, no. 1-3, pp. 334-344, 2010.

[46] G. Hetsroni, "Particles-turbulence interaction," International Journal of Multiphase Flow, vol. 15, no. 5, pp. 735-746, 1989/09/01/ 1989.

[47] A. Meriläinen et al., "Influence of particle size and shape on turbulent heat transfer characteristics and pressure losses in water-based nanofluids," International Journal of Heat and Mass Transfer, vol. 61, pp. 439-448, 2013/06/01/ 2013. 